Revista Iberoamericana, Vol. LXXIV, Núm. 225, Octubre-Diciembre 2008, 879-895

\title{
HACIA UN VERBO QUEER
}

\author{
POR \\ Amy Kaminsky \\ University of Minnesota
}

Este ensayo propone un verbo queer para el español, el neologismo "encuirar". Reminiscente del verbo encuerar y evocandor del acto de desnudar, encuirar significa des-cubrir la realidad, retirar la capa de la heteronormatividad. ${ }^{1}$ Encuirar propone desvestir no solamente para mostrar la realidad debajo de la vestidura engañosa -el outing clásico-, sino también como una forma de deconstrucción. Cuestiona la estabilidad de las normas. Revela la inestabilidad de la identidad y, paradójicamente, revela también la necesidad de crear y defender identidades alternativas para sobrevivir en una cultura regida por la identidad normatizada.

La crítica de la literatura y cultura lésbico-gay/queer, a la cual está dedicado este número de la Revista Iberoamericana, es un fenómeno más bien reciente en el campo latinoamericano. Daniel Balderston acierta al sostener que no se trata de una falta de especialistas en el campo, sino de las mismas estructuras institucionales que han retrasado las investigaciones y la enseñanza sobre la materia (95). Aunque actualmente el uso del término queer en su función adjetival -por ejemplo, "la teoría queer"-es bastante aceptado entre los críticos culturales y literarios en nuestro campo, la presencia viva del cuerpo queer entre nosotros sigue provocando ansiedades. La homofobia ha sido, y sigue siendo, un freno poderoso para los que quieren dedicarse a los estudios queer en las culturas y literaturas latinoamericanas.

Cuando empecé a investigar la escritura lésbica durante los ochenta, no fue solamente porque me di cuenta de que no se podía hablar de los temas que me fascinaban, entre ellos la literatura femenina, la sexualidad de la mujer y las relaciones del poder, sin investigar el significado del lesbianismo en la cultura en general. También pensaba que, por ser menos vulnerable que much@s colegas,

1 Este término es fruto de una conversación con los poetas Noni Benegas y Mario Merlino, argentinos expatriados en Madrid, cuya animada participación en el juego de inventar un vocabulario es sólo parte de su encanto. Les agradezco su buen humor y su amor a las palabras, a las ideas, y a la poesía. También quisiera expresar mis gracias a Ana Paula Ferreira, Joanna O’Connell, Barbara Weissberger y sobre todo a Román Soto, por su generosidad intelectual al leer y comentar este ensayo antes de su publicación. 
tenía la responsabilidad de abarcar la materia. ${ }^{2}$ Disfrutaba del tenure, ${ }^{3}$ de un puesto en un departmento no de español, sino en uno de estudios de la mujer, y de un marido -o sea, de una señal visible de mi heterosexualidad. ${ }^{4}$ La homofobia que reinaba en el departamento de español y portugués de mi universidad, que amenazaba a mis colegas homosexuales no podía hacerme mucho daño; el hecho de que algunos dinosaurios hispanistas les advertieran a sus estudiantes que debían de mantener su prudente distancia con respecto a las lesbianas de mi departamento (entre las cuales me contaban, a pesar del dicho marido), sólo provocaba risas. Sin embargo, poc@s colegas en nuestro campo han tenido mi buena fortuna en cuanto a su ubicación institucional. Aunque hoy en día es un poco menos fácil blandir abiertamente las armas homofóbicas -gracias en parte a la legitimación en muchas universidades norteamericanas de los estudios LGBT-Q (lésbico, gay, bisexual, transgénero-queer) - es todavía arriesgado especializarse en la materia en muchas instituciones académicas.

La homofobia todavía silencia a muchos hispanistas en los Estados Unidos y, en mayor grado, en Latinoamérica misma. Sería útopico creer que las universidades americanas, sean del norte o del sur, no hospedan los prejuicios, las ansias y la violencia latente frente a la sexualidad transgresiva, o que la inquietud provocada por la homosexualidad en nuestras culturas no tiene sus repercusiones negativas en el ambiente académico. ${ }^{5}$ Por eso, el florecimiento reciente de los estudios lésbicos, gay y queer en torno de la literatura y la cultura latinoamericana representa la valentía intelectual y personal de muchos individuos al abrir el campo en las instituciones académicas. ${ }^{6}$

2 La arroba, como indicio no sexista del sustantivo, ya es de uso común en España. La primera vez que la vi fue en 2002, en un graffiti anarquista que decía: “Tod@s somos legales” refiréndose a una ley que se había propuesto para castigar a los inmigrantes indocumentados. En 2005, las bibliotecas municipales de Madrid han puesto un cartel que promueve la lectura infantil que dice "Si tú lees, ell@s leerán”. O sea que sólo han pasado tres años entre la incursión anarquista en el lenguaje hasta su adopción por la cultura oficial.

3 Nota del Editor. En el sistema universitario estadounidense, los profesores generalmente son contratados por seis años. Durante este período de prueba -llamado tenure-track- se deben hacer méritos para obtener la permanencia definitiva: publicar, enseñar, participar en la vida académica de la institución, etc. Obtener el tenure significa que la persona logró la permanencia definitiva en la universidad, es decir un contrato vitalicio de trabajo.

4 Salir del armario como heterosexual es complicado; por un lado puede servir para proteger a un@ del oprobrio homofóbico. Aquí sigo los consejos de mis colegas lesbianas que me han dicho que no debo permitir que se me atribuyan una identidad y una historia que no me merezco.

5 En Europa, y sobre todo en España, la política cultural ha cambiado mucho en el último cuarto de siglo, dando apertura no sólo a los desfiles del orgullo gay en las grandes ciudades, sino también a la aprobación de la mayoría del país del matrimonio y de la adopción gay. Sin embargo, las estructuras universitarias son lo suficientemente rígidas como para hacer difícil el estudio de temas queer.

6 Carlos Muñoz informa que Milagros Socorro, escribiendo en el periódico El Universal, usa el término GLBT: "Una semana después de la marcha, El Universal introduce el término GLBTs en la sección 
La incorporación del adjetivo anglosajón en una formulación española no es demasiado chocante; muy pocos acusanya a @@s teóric@s de lo queer de pertenecer a un frente nuevo del imperialismo cultural, a diferencia de lo que ocurrió al aparecer términos como "gender" y su traducción literal, "género", asociados con la teoría feminista durante los ochenta del siglo pasado. Es posible que en esta nueva época neoliberal y globalizada, la amenaza lingüística, practicada por académicos, no provoque grandes inquietudes. También es concebible que el hecho de que se haya gastado tanta energía en cuestionar la incorporación y traducción de términos feministas provenientes del inglés haya disipado las fuerzas para otra batalla sobre semejante materia. El lenguaje feminista anglosajón provocó mucha bulla, pero después, ya matizado, fue incorporado al vocabulario crítico latinoamericano sin destruir la materia prima de la cultura. Sin lugar a dudas, el camino que abrió la crítica feminista en el estudio del género y de la sexualidad femenina en la producción cultural latinoamericana ha sido estudiado y ampliado por los críticos y teóricos de la sexualidad transgresiva. Éstos, por lo tanto, han podido adoptar un lenguaje crítico acerca de lo lésbico-gay/queer sin mayores problemas.

No obstante, el término tripartito "lésbico-gay/queer" representa la apropiación de un vocabulario extranjero en varias etapas de asimilación. Por un lado, el adjetivo "lésbico" es plenamente español, aunque quizás resucitado y provisto de una nueva vitalidad política y teórica gracias a un movimiento social internacional. Por otro, la desaparición de las cursivas al escribir el término "gay" señala tanto la adopción de la palabra extranjera por parte de la comunidad a la cual se refiere como su aceptación (quizás un poco precaria todavía) en el ámbito académico. "Queer", en cambio, escrito en cursivas, encarna su propia rareza, su estado ambivalente. Oscar Montero comenta la casi inexistencia del término en el discurso críticoliterario hispano (114). Parecido al simulacro (la copia que carece de original), es una palabra prestada del inglés para referirse a un concepto que todavía no ha cobrado su significado completo en español; la no-traducción de un signo medio inexistente. En su totalidad, el encabalgamiento adjetival "lésbico-gay queer" es un indicio semántico de la condensación de una trayectoria teórica que en los estudios literarios y culturales anglosajones tuvo un proceso mucho más lento.

George Yúdice, quien utiliza la palabra queer para referirse a la performatividad y la identidad gay, ejemplifica el uso académico corriente del término (346). Yúdice se refiere a una gama de identidades que dependen de ciertas prácticas de, y actitudes hacia, el placer. La cuestión de la naturaleza de esas identidades -si es parte de la esencia del sujeto, si es adquirida a través de un proceso intrapsíquico,

de opinión, junto con el tema de la discriminación antihomosexual” (249). Escribe Socorro: "Ese grupo se reconoce por la sigla GLBTQS \& GH (gays, lesbianas, bisexuales, transgéneros, queers, simpatizantes y gays honorarios) [...]” (cit. en Muñoz 249). 
o si es performativa- también ha ocupado a los especialistas (aquí me interesa menos la etiología de la sexualidad no normativa, es decir, cómo se produce, cuál es su epistemología: cómo se conoce y se entiende). ${ }^{7}$ Según nos cuenta Foucault, en sus inicios la homosexualidad, por ejemplo, describía una práctica sexual, no una identidad. Lo que antes nombraba una práctica de placer ahora clasificaría una identidad sexual, y el término ha sido reclutado para categorizar hasta textos y prácticas críticas. Se trata de una constelación de significados y referencias que incluyen la práctica sexual del cuerpo y la práctica intelectual sobre un corpus, pasando por la identidad, en una cronología que se niega a la estabilidad. Hablar de un hombre gay, o de una mujer lesbiana, implica unas prácticas homoeróticas íntimas, lo que hace la gente entre las sábanas, en los bares y en los parques; pero termina en una identidad cultural -no lo que un@ hace, sino quién es. Hablar de una práctica literaria gay o lésbica suele implicar la representación de las prácticas e identidades, preferentemente por los autonombrados gay y lesbianas. De la persona gay a la película gay (¿o es al revés?), de la mujer lesbiana a la novela lésbica (¿o viceversa?), caemos en la trampa de las identidades fijas. A pesar de la futilidad de la empresa de encontrar la salida del laberinto de la identidad que se desdobla en la práctica, vale la pena explorar sus muchas rutas interesantes y su paisaje atractivo, original y seductor.

En nuestro campo, por razones de compresión histórica, lo queer se asimila a lo lésbico-gay. Sin embargo, la teoría queer desarrollada con más amplitud y más tiempo en las academias norteamericanas mantiene que lo queer es precisamente el concepto que pone en tela de juicio los binarismos ejemplificados por la oposición lesbiana-gay. Si bien el término queer se destaca por su labilidad -igual que "homosexual", "gay" o "lesbiana", queer puede referirse a una identidad autorial o a una temática; también puede nombrar un proceso, un modo o una actitud-, “'Lesbiana' y 'gay”” son identidades que parten de un paradigma moderno, basado en el concepto de un sujeto estable, mientras que la perspectiva más bien posmoderna posiblitada por el vocablo "queer" rechaza tanto la estabilidad del sujeto como una teoría arraigada en una concepción esencialista de la identidad. Igual que en otros campos de estudios sobre la producción cultural de grupos marginados (por ejemplo, la mujer, la diáspora africana), las investigaciones sobre temas que hoy calificaríamos como queer empezaron con un enfoque en la identidad. ${ }^{8}$

7 Los debates sobre la etiología de la homosexualidad, la cual ha sido también un tema importante en los estudios queer, revelan una división entre biologistas y construccionistas. Aquéllos suelen ser gay, y éstos, lesbianas, lo cual implica una diferencia en el carácter sexual (en términos generales) entre los géneros. La experiencia de que uno nace gay parece ser más común entre los hombres que entre las mujeres, aunque la diferencia no es absoluta, ni mucho menos.

8 La analogía ha sido un motor poderoso en el encuiramiento del entorno político y cultural. Por eso, el cuerpo queer se ha comparado con el cuerpo femenino, o con el cuerpo racializado, los cuales marcan la divergencia de la norma de la masculinidad heterosexual y blanca. Sin embargo, a diferencia de 
La búsqueda de textos escritos por gays y lesbianas, a partir de indicios de que tal o tal autor fuera gay (lo que Balderston [6] llama la chismografía), y de las representaciones del deseo gay y lésbico ha preocupado a muchos estudiosos de la problemática y sigue representando la mayor parte del trabajo en el campo. No obstante, el fundamento de la identidad que los subyace resulta mucho menos robusto de lo que parecía al principio. Semejante a los estudios de la mujer, que terminan cuestionando la categoría del género, y los estudios negros que abren el paso al cuestionamiento de la categoría "raza", los estudios LGBT acaban cuestionando las bases mismas de la identidad. ${ }^{9} \mathrm{La}$ "T", por transgénero, de la formulación LGBT, implica que la identidad sexual es mutable. Tal mutabilidad apoya la teoría posmoderna en su cuestionamiento de la estabilidad del sujeto, en la postura antiesencialista que mantiene que la identidad se produce en la cultura, y en la idea de que la identidad es un fenómeno performativo. Si bien la práctica de lo que Balderston llama la chismografía (6)nos permite identificar al poeta gay o a la cuentista lesbiana, con la pérdida de la base sólida de la identidad fija resulta difícil etiquetar el texto como "gay" o "lésbico". ${ }^{10}$

No obstante, el deseo transgresivo es real; los actos sexuales sí llevan su etiqueta, y las instituciones culturales condenan y castigan a algunos y premian a otros. Las categorías de la sexualidad no tienen que ser rotundas, sempiternas y fijas para tener un efecto muy real en el mundo. No hemos dejado atrás el momento histórico en que debe mostrarse y analizarse la temática gay o la presencia lesbiana en la literatura y el cine. Sin embargo, vale la pena cuestionar el contenido de tal temática o de tal presencia. No se limita, seguramente, a la representación del deseo transgresivo y de la experiencia directamente relacionada con el vivir ese deseo (el salir del clóset, la exploración del placer sexual, las historias del sida). También sigue siendo necesario insistir en la contribución histórica de gays y lesbianas a la

otros cuerpos subalternos, el cuerpo queer es el efecto de su propio deseo, de un deseo transgresivo. Aunque todos los cuerpos subalternos se producen dentro de las normas culturales, y en concierto con los otros, no son estrictamente paralelos. El cuerpo queer no se concibe sin la noción de la heteronormatividad y el axioma de que el mundo se divide entre machos y hembras, cuyo deseo tiene que ser siempre para su contraparte. El cuerpo queer también se define por sus prácticas sexuales y parasexuales: las prácticas e intereses que sin ser sexuales se asocian con un género u otro.

9 Un resultado de este cambio es la creciente incorporación en el campo de especialistas queno pertenecen a los grupos que dieron ímpetu a su formación. Cada vez más hombres prestan atención a la teoría feminista, más blancos a los estudios de la raza. De igual manera, no todos los que estudiamos la temática queer practicamos una sexualidad transgresiva.

${ }_{10}$ Para una discusión más amplia de este problema, véase Kaminsky, "Cristina Peri Rossi and the Question of Lesbian Presence”, en Reading the Body Politic. Aquí, desde luego, el verbo "identificar" cobra cierta ironía. El término fantasma en este caso, el que aparece para desaparecer, es "bisexual”, una identidad controversial en el ambiente lésbico/gay, por su aparente lealtad a cierto grado de heteronormatividad o, según otros, por su falta de disponibilidad a aceptar una identidad plenamente gay o lésbica. 
cultura e imprescindible analizar la estética que se asocia con el mundo queer, desde las normas de la autorepresentación hasta el camp. ${ }^{11}$ La proliferación de artículos, libros, monografías y antologías de estudios sobre el tema muestra lo robusto que es el deseo de analizar la producción cultural queer en el ámbito latinoamericano.

La práctica del deseo se asocia con la identidad sexual, sea ésta ententida de una manera esencialista, cultural o performativa. La consideración textual de tal identidad produce un espacio queer en el juego autor-texto-lector. Por lo tanto, la interacción entre el placer textual y el erotismo en este espacio queer merece un estudio aparte.

En pocos años el campo de los estudios latinoamericanos queer ha crecido en visibilidad y en sofisticación teórica. Desde los primeros pasos en que los críticos identificaron como lésbicos o gays a un puñado de textos y escritores, hemos pasado a pensar la relación entre la práctica sexual y la cultura, la nación y la producción de la identidad. Ha sido de una importancia extraordinaria nombrar la presencia de la homosexualidad y señalar la existencia de personas lesbianas y gays en el entorno latinoamericano. El estudio panorámico de David William Foster, Gay and Lesbian Themes in Latin American Litearture, nos ha proporcionado un corpus de textos de tema gay y lésbico, y otros críticos han seguido su ejemplo. Han arrancado del armario a textos más o menos abiertamente gay, subtextos que anteriormente sólo un grupo reducido y escondido había reconocido, y escritores cuya vida incluía, parece, el homoerotismo. Los poemas homoeróticos de Xavier Villaurrutia saltan a la vista; la nueva lectura de Gabriela Mistral empieza con la reevaluación de su biografía (Fiol-Matta).

Nuestros estudios se han profundizado en su análisis de estos textos, recuperándolos por su importancia dentro del canon literario y reclamando un espacio abiertamente gay/lésbico, como lo han hecho Balderston y Quiroga en Sexualidades en disputa: homosexualidades, literatura y medios de comunicación en América Latina. Este libro da el próximo paso; es decir, buscar en la temática gay un vínculo con los discursos dominantes. Otros críticos, como Oropesa, en su estudio de los Contemporáneos, que ubica a varias figuras literarias en el ambiente gay mexicano, y Sifuentes Jáuregui en su trabajo sobre la historia de "los 41", participan en la codificación de la historia política gay en la historia cultural y lingüística mexicana. JoséPiedra y Sylvia Molloy (1992), entre otros, han investigado y teorizado el interés que tiene la nación recién formada en mantener su heteronormatividad. Molloy expone, con su elegancia retórica habitual y su análisis impecable, el placer y el pánico experimentados por algunas de las figuras canónicas del modernismo frente

${ }^{11}$ En una entrevista en Revista Ñ, el chileno Pedro Lemebel, rechaza las normas norteamericanas de la homosexualidad, entre ellas el término "gay”, por ser demasiado conservadoras. Dice que sólo se puede salir del ropero cuando hay ropero en casa, es decir, que la intimidad forzada de la miseria de ciertos sectores de su país no deja espacio para los secretos sexuales. 
a la amenaza de Oscar Wilde, y Piedra es simplemente brillante en su ensayo sobre la ansiedad que produce el concepto de los maricones nacionales en el contexto puertorriqueño.

Por otra parte, el concepto de lo queer representa un paso teórico fuerte en la formación -y en el cuestionamiento- de una identidad alrededor de las prácticas sexuales. Los términos gay y lesbiana, los más frecuentemente utilizados para referirse a una sexualidad que rehúsa las limitaciones de la heteronormatividad, repiten, sin embargo, una división fundada en el género. ${ }^{12}$ Tal división le sirve de andamio a la cultura heterosexual, que por otro lado es normalizada y controlada bajo el régimen de un binarismo absoluto y jerarquizado. “Queer”, en cambio, pretende desestabilizar el binarismo que impone la heteronormatividad. Hombre y mujer, gay y lesbiana, macho y hembra -hasta heterosexual y homosexual-pierden su dualidad absoluta en el término singular y múltiple, “queer”. Transgredir las normas del deseo, sean cuales sean éstas, es suficiente para reclamar el nombre queer. Por ejemplo, en cuanto hagan borrosas las fronteras establecidas por la cultura heteronormativa, “marimacho" y “maricón” pueden ser no solamente términos de desprecio lanzados por una cultura homofóbica, sino identidades (provisionales, vale decir) queer. La identidad única, concretizada en un sistema binario -la propuesta fundamental del estructuralismo y el emblema y paradigma moderno- se dispersa. Deja de respetar sus propias fronteras. La identidad concebida dentro de la posmodernidad es mutable, migratoria y desobediente, o sea profundamente queer.

Si bien por un lado la categoría queer es inadecuada para fundar una teoría magistral (o quizás sería mejor sostener que es necesariamente antimagistral), es por otro lado una ubicación política y cultural imprescindible. ${ }^{13}$ Incluye, supera, y al final socava lo gay, lo lésbico, lo bisexual y lo transgénero, por no hablar de lo heterosexual. ${ }^{14}$ La revelación de la presencia de la cultura producida por gente queer es fundamental para el proceso de lo que voy a llamar el "encuiramiento" del individuo transgresor. El estudio de esta presencia, es decir su legitimación

\footnotetext{
${ }^{12}$ Este trazamieno del mapa gay/lesbiana sobre la estructura heterosexual, hombre/mujer, ha sido base de una controversia importante. Monique Wittig, por ejemplo, sostiene que "lesbiana" no es equivalente a "mujer" -que, al contrario, la lesbiana rechaza todo lo que significa "mujer". Gayle Rubin y Teresa de Lauretis, entre otras, argumentan que butch y femme no son tristes imitaciones de la distinción heteronormativa. A pesar de la reconfiguración del concepto del género dentro del ámbito teórico LGBT-queer, sin embargo, la dualidad gay/lesbiana comparte con hombre/mujer la forma binaria y un contenido sexual.

${ }^{13}$ Igual puede ser superflua. Una vez escuché una presentación hecha por la teórica queer Eve Kosofsky Sedgwick en la que preguntó retórica y cómicamente: ¿dónde está el Platón queer? ¿Dónde el Alejandro Magno queer? ¿Dónde el Shakespeare, dónde el Miguel Ángel queer?

${ }^{14}$ Por eso reconozco que la resistencia contra el matrimonio y los derechos civiles gays corresponde a una inquietud profunda hacia una amenaza real, no tanto a un sistema sexual sino a un régimen epistemológico.
} 
dentro del mundo académico y la valoración de una historia de la cultura gay y lésbica, sirve de apoyo al movimiento para la liberación gay-lésbica-bisexualtransgénero, iluminando las contribuciones de gente que practica una sexualidad no normativa. Por eso es tan importante reconocer (y no suprimir) la temática gay de un Salvador Novo, el subtexto lesbiano de una Teresa de la Parra, el pánico homosexual de un Rodó. ${ }^{15}$

En términos más amplios, sin embargo, lo queer se caracteriza por una serie de prácticas (por provisionales que sean) que en cualquier momento se consideran inaceptables. La normalización de ciertas practicas homosexuales (las que parecen semejantes a prácticas de la heterosexualidad normativa, como por ejemplo el emparejamiento monógamo, reconocido por el estado, por la comunidad y por la iglesia) puede llevar a cierto nivel de desqueerificación..$^{16}$ Es posible que el lema "We're here, we're queer, get used to it", popularizado por ACT-UP, contenga su propia contradicción. ${ }^{17}$ Una vez que la sociedad se acostumbre a lo queer, y a los queers, es posible que éstos dejen de serlo. Reconozco que estamos muy lejos de llegar a esta situación. A pesar de la legalización del matrimonio gay en algunos países europeos y en unos cuantos municipios norteamericanos, la homofobia no ha sido derrotada. Y aunque hay gays cristianos que practican su religión en una iglesia que los acepta completamente y lesbianas rabinos con congregaciones que las quieren, sus correligionarios hostiles a la sexualidad queer siguen vociferando su oposición en términos tajantes. La liberación queer sigue siendo un objectivo político, no un hecho real.

Sin embargo, el anhelado reino abierto de lo queer también presenta incomodidades. Si bien queer significa transgresión, abre también el paso a prácticas que muchos (entre ellos, yo) encontramos abominables, prácticas que producen o reproducen la desigualdad y el abuso de poder. Una práctica queer que no reconozca la perduración de las fórmulas de desigualdad de la cultura dominante me parece miope y peligrosa. Por mucho que la política queer quiera alejarse y diferenciarse de la cultura heteronormativa, es también un producto de esa cultura, cuyos sistemas de desigualdad ni comienzan ni terminan en cuestiones de sexualidad. Por lo tanto, habrá de sospecharse de una teoría queer en la que las voces más fuertes

\footnotetext{
${ }_{15}$ Me refiero a estudios por Salvador Oropesa, Sylvia Molloy (en Bergmann y Smith 230-256) y Óscar Montero.

${ }^{16}$ Por eso, diría que las prácticas homosexuales institucionalizadas en la Grecia de Platón y Sócrates no eran queer. Sin embargo, es importante reconocer que forman parte de una herencia cultural de lo que hoy se considera una sexualidad transgresiva.

${ }^{17}$ Nota del editor. El lema podría ser traducido al castellano como: "Aquí estamos, somos queer, váyanse acostumbrando”.
} 
pertenezcan a gays y no a lesbianas, a blancos y no a gente de color, a personas de clase acomodada y no a las de las clases populares. ${ }^{18}$

Falta mucho antes de que los binarismos asediados por el pensamiento y la actuación queer sean derrotados. Uno de los grandes desafíos para una práctica literaria y cultural queer y para la crítica de tal práctica es la cuestión de la producción literaria teórica lesbiana. El esencialismo estratégico que propone Gayatri Spivak para reconciliar su inclinación posmoderna con su política poscolonial puede ser útil en la reconciliación del deseo de abandonar las categorías sexistas y heteronormativas en un contorno político que contiene fuertes residuos de prácticas de poder que erosionan lo que les pertenece específicamente a las lesbianas. Por otra parte, proponer que toda transgresión sea una forma de práctica queer también amenaza con diluir el énfasis en el cuerpo y el deseo. Lo queer no debería nunca perder su aspecto lúdico, sensual y erótico. ${ }^{19}$

Al romper el silencio alrededor de su sexualidad y pronunciar su deseo, tanto la crítica como 1@s escritores cuestionan la heteronormatividad que respalda a la sociedad contemporánea. Al salir del clóset e insistir en su presencia, el sujeto queer (sea gay o lesbiana, bisexual o transexual) produce una inquietud cultural. Altera (en todos los sentidos de la palabra) la realidad que lo rodea y en la cual participa. Ahora bien, toda esta actividad creativa, crítica, pedagógica y política requiere un verbo activo que lo exprese. Actualmente, el término “queer” mismo es materia de experimentación dentro del ámbito hispano, y aunque todavía se ven muy pocos estudios académicos que utilicen la palabra, ${ }^{20}$ en la internet, más allá del mundo de los impresos y los especialistas, ya se está jugando con ella. He visto en un lugar ya desaparecido de la internet el desdoblamiento visual y auditivo del vocablo “cuirpo". Al utilizar la ortografia española para producir el sonido de la palabra inglesa queer, se condensa la idea del cuerpo queer en una sola palabra macarrónica de una manera económica, elegante y humorística. Otra escritora de la red, la española Fefa Vila, invierte este procedimiento, utilizando la ortografía

${ }^{18}$ En la estética queer del camp, por ejemplo, domina lo gay, quedando al margen lo lésbico. Es decir que tal estética refleja una masculinidad queer, que aun siendo alternativa, está arraigada en la feminidad exagerada y hasta en la hipermasculinidad. Por lo tanto, mantiene una relación compleja con, y contra, las normas performáticas del género.

${ }^{19}$ Erótico en el sentido amplio que propone Audre Lorde en su ensayo seminal "Los usos de lo erótico", en en cual el erotismo conlleva placer y poder.

${ }^{20}$ Cuando buscaba libros sobre teoría queer en una librería gay de Chueca, el barrio gay de Madrid, el chico que me atendió -muy sofisticado en su análisis de la situación social y política y al corriente de los libros en su establecimiento- simplemente no conocía la palabra queer, y los libros que me mostró eran más bien de historia y sociología. Sólo encontre uno, escrito por un filósofo, que usaba el término "homosexual". Sin embargo, los grandes movimientos político-sociales requieren, y por lo tanto impulsan, la evolución lingüística, si bien de una manera desigual. En los meses que han transcurrido entre la escritura inicial de estas relexiones y el momento presente, se ha visto más experimentación lingüística referente a la sexualidad dentro del ámbito universitario. 
inglesa para crear el vocablo "queerpo", es decir, el cuerpo queer, en este caso del cuerpo mutante del ciborg. Por otra parte, el fanzine electrónico "Queeremos Saber" juega visualmente con la similitud ortográfica entre la raíz de la palabra que denota el deseo, “querer”, y el adjetivo/sustantivo queer, implicando que el conocimiento que se anhela es precisamente un conocimiento queer.

La española Paloma Fernández Rasines, en un artículo sobre la representación lesbiana en la televisión y la internet, hace referencia al término en su sentido verbal y utiliza una formulación que revela lo forzado que es: "hacer queering". ${ }^{21}$ Que yo sepa, sin embargo, el término "queer" como verbo transitivo, es decir, "to queer" alguna cosa, no ha penetrado todavía en el ambiente teórico latinoamericano, y los matices que separan lo gay y lo lesbiano de lo queer representan una nueva frontera en muchos análisis. "To queer" (es decir, "hacer queering” en la formulación de Fernández Rasines) señala el paso de nombrar una identidad clandestina y sacarla del armario a activar un proceso transformativo en la cultura.

La formulación "hacer queering" capta tanto el impulso activo del verbo en castellano como el del gerundio en inglés. Este último, por su parte, ocupa el espacio indeterminado entre verbo y sustantivo -un espacio queer que inquieta a las categorías establecidas. Al mismo tiempo, la yuxtaposición de los dos idiomas produce su propia energía; sugiere la urgencia del gesto crítico/analítico, aunque todavía no exista el vocablo preciso que lo exprese adecuadamente en su propio fondo lingüístico. Sin embargo, la formulación tampoco es una traducción (di) recta; es decir que hasta la traducción es un poco queer. En inglés, los teóricos y críticos queer no "hacen queering" (“do queering”): intransitivo. Queerean ("they queer"): transitivo. ${ }^{22}$

Escribiendo en inglés en su tomo de ensayos sobre lo que llaman "hispanismos" y "homosexualidades", Sylvia Molloy y Robert McKee Irwin hablan de su objetivo:

This collection would like to bring hispanisms into homosexualities, would like to propose queer readings of Spanish American literatures and cultures, but would also seek to queer univocal constructions of mainstream homosexualities with its own, oblique, not easily assimilated hispanisms. (xvi)

${ }^{21}$ Fernández Rasines observa que los que hacen ese tipo de trabajo y por lo tanto utilizan el lenguaje de lo queer suelen haberse formado en Estados Unidos: "Por lo que he podido ver en el Estado español, quienes hacemos queering en nuestras respectivas disciplinas hemos sufrido una suerte de seducción después de habernos formado en el entorno académico norteamericano principalmente".

${ }^{22}$ Un paralelo inexacto de la formulación verbal "to queer" podría ser "pervertir”, término que, gracias a su doble sentido de "distorsionar" y "corromper", pudiera compartir el espíritu de recuperación de términos de oprobio que se refieren a la homosexualidad. Sin embargo, dado que ese término no forma parte del vocabulario rescatado dentro del ambiente gay, no está disponible para estos propósitos. 
Lo inusitado del proyecto de Molloy y McKee Irwin reside en la ubicación de lo queer -no en los textos ni en los autores, sino en la práctica crítica. ${ }^{23}$ Sin embargo, el párrafo mismo se resiste a la traducción: "Esta colección”, dice, "quisiera introducir los hispanismos a las homosexualidades, quisiera proponer lecturas queer de las literaturas y culturas hispanoamericanas, pero también quisiera [y aquí falla la traducción, ¿qué hacer con el verbo queer?] las construcciones univocales de las homosexualidades dominantes con sus propios hispanismos poco asimilados, oblicuos".

El verbo queer lo es por lo que es (un sustantivo que transgrede las fronteras gramáticas para convertirse en verbo) y por lo que no es (un vocablo autóctono). Es queer en el sentido de inusitado, pero también en el sentido de desestabilizante. En principio, "queer" en inglés es un adjetivo; significa "raro". Por lo tanto, al ser reclutado para servir de sustantivo o de verbo, se autodescribe, y en español es un verbo aún más raro de lo que es en inglés, donde por lo menos tiene una historia. "To queer" en inglés es argot por "inquietar", "alterar" y aun "destrozar". Este significado ha corrido paralelo al sustantivo históricamente peyorativo, “queer”, es decir, "homosexual”. La teoría y la práctica queer marcan el espacio verbal donde se entrecruzan el verbo y el sustantivo. Es el/la queer, quien -por su presencia y su desafío- inquieta y altera la heteronormatividad hegemónica. El mero hecho de adoptar el peyorativo "queer", de pronunciar su propia transgresión sexual a través de este vocablo, es un acto queer, una incursión en la heteronormatividad que la inquieta.

El verbo queer que propongo, "encuirar", desafía también la normalidad. Revela el efecto de la normalización y la producción de un estado que se pretende natural. ${ }^{24} \mathrm{Al}$ usar en castellano el vocablo queer en su función verbal, encuirar implica una transitividad, una práctica, un análisis; una distorsión que revela otra distorsión previa; una nueva perspectiva sorprendente y placentera.

Ya era hora de encuirar el hispanismo, de "imponer[le] la disidencia sexual", en las palabras de Molloy e Irwin. O, mejor dicho, de nombrar la práctica, porque en

\footnotetext{
${ }^{23}$ Molloy y McKee Irwin notan que "en este momento no es un gesto impertinente sino un paso desestabilizante, una fractura propicia -en fin, una invitación para leer de nuevo [una literatura] moribunda por su [...] canonicidad" (xi). El agente de tal relectura no se nombra en esta frase, pero aquí y en otros textos se supone que es homosexual. Sin embargo, Molloy y McKee Irwin dejan un espacio para una agencia más amplia, que va más allá de la identidad queer sin perderla como eje. Comentando sobre el grupo de especialistas que se reunía en los congresos sobre estudios queer en Yale, notan: "muchos de nosotros, panelistas y público, éramos queer, organizadores y ponentes éramos en muchos casos españoles, latinoamericanos o latinos, todos nosotros enseñábamos literaturas españolas y escribíamos sobre esas literaturas” (ix). Es decir que la identidad universalmente compartida es la de hispanista, basada en una práctica académica y un interés -intelectual, personal-en las cuestiones presentadas alrededor de la disidencia sexual.

24 Esta definición se basa en la de Warner, en Fear of a Queer Planet.
} 
efecto hace tiempo que la crítica cultural y literaria ha estado encuirando su entorno. David William Foster gesticula hacia el encuiramiento de la literatura latinoamericana trastocando el adjetivo y el verbo en Sexual Textualities:Essays on Queer/ing Latin American Writing, y Rosemary Feal, en su ensayo sobre "Casa tomada", encuira a un escritor quizás excesivamente heterosexual, Julio Cortázar.

Si bien una práctica queer propone deshacer la (no tan) breve cárcel de los términos identitarios (o de la identidad terminante), vale la pena investigar su función. La exploración del laberinto de las identidades sexuales transgresivas, sean de personas o de textos o de prácticas, consciente de que la identidad sexual de un texto es una metáfora y la de una persona bien puede ser una ficción (es decir una narrativa formulada bajo unas pautas culturales preestablecidas y naturalizadas), es una empresa profundamente queer. Requiere una visión irónica, un sentido lúdico y un compromiso con la provisionalidad. Su proyecto es desestabilizador; parecido al de la figura del estafador (trickster) de muchas culturas tradicionales, que mezcla lo serio con lo cómico, lo masculino con lo femenino, el placer con la destrucción, la vida con la muerte.

Ponerle una identificación queer a un sujeto (sea una persona, un texto, una práctica) pretende calificarlo dentro de una taxonomía que contradice y socava la característica fundamental de lo queer, es decir la inestabilidad, lo indeterminado, la transgresión "misma (semejante posición argumentaron las feministas posestructuralistas, las de la llamada "diferencia”, en cuanto al término “femenino”, que según ellas, caía fuera de la economía patriarcal)”. No obstante, sin tal identificación provisoria el rescate de la cultura queer para la crítica literaria y cultural se vuelve imposible.

Es insuficiente, sin embargo, encuirar los estudios latinoamericanos sólo al nivel de los especialistas. Hace falta llevar el encuiramiento a las aulas, como propone Daniel Balderston. Para hacerlo, Balderston elabora el concepto de "la pedagogía de lo reprimido", haciendo referencia irónica y a la vez agradecida a la obra clásica de Paulo Freire sobre la relación entre colonización, pobreza y alfabetización, $L a$ pedagogía de los oprimidos (Balderston, El deseo, enorme cicatriz luminosa 95-98). "Los oprimidos" de Freire, pobres, campesinos, analfabetos, son sujetos históricos. La pedagogía a la cual se refiere es una práctica de alfabetización y concienciación y una filosofía pedagógica y política. La práctica pedagógica que comenta Balderston es más bien una ausencia, por lo menos en las aulas latinoamericanas; está casi tan reprimida como la identidad sexual a la cual se refiere. Los últimos años, sin embargo, representan una apertura hacia la materia. La Coordinadora Universitaria por la Diversidad Sexual (un colectivo de activismo queer universitario) publicó el primer número de la revista Torcida en 2005, respaldado por la Universidad de Chile. En México, Adriana Ortiz Ortega, del Programa Interdisciplinario de los Estudios de 
la Mujer (PIEM) del Colegio de México, dirigió un estudio transglobal sobre la enseñanza sobre sexualidades y género que incluía programas y cursos en México, Argentina, Brasil y Chile. En Argentina, se ha abierto el campo de los estudios de la sexualidad en el Área de Estudios Queer en la Universidad de Buenos Aires y el de la Universidad de La Plata. ${ }^{25}$

El juego entre estos dos conceptos ligados y separados por la etimología es significante. "Lo reprimido" es un término psicoanalítico; se refiere a eso que en un individuo o en una cultura se esconde, se niega, o que se mete en el rincón más oscuro del armario de la subconciencia o de los barrios más abyectos de la urbe. Por definición, no se elimina y, según Freud, siempre roetorna. La homosexualidad es una instancia por excelencia de lo reprimido. "Los oprimidos", en cambio, son sujetos políticos, personas que sufren bajo un régimen por definición injusto (de no serlo, no habría oprimidos). La opresión, definida por la filósofa norteamericana Marilyn Frye, es un sistema institucionalizado, dirigido a cierta clase de individuos a través de un discurso (el cual incluye unas prácticas interrelacionadas) que limita la libertad de cualquier individuo que pertenezca a ese grupo determinado. Abundan los ejemplos: los negros y el racismo; las mujeres y el sexismo; los homosexuales y el heterosexismo o la homofobia). En la sociedad heterosexista, la opresión del sujeto homosexual es una práctica de la represión de la homosexualidad. Al oprimir a los homosexuales, la sociedad reprime su propio contenido homosexual, siendo éste no sólo los individuos que practican una sexualidad "diferente” sino también las prácticas simbólicas que representan tal sexualidad, por ejemplo, la transgresión de fronteras degénero a través dela presentación del cuerpo por medio de la indumentaria, la manera de caminar o la cualidad de la voz.

Para encuirar el espacio cultural o la práctica crítica, es imprescindible partir de las dos fuentes: la política, que resiste la opresión, y la psicoanalítica, que expone la represión. La primera nos indica que siempre ha de estar presente el cuerpo gay, el sujeto lesbiano u homosexual, la temática expresamente gay o lésbica sobre la experiencia tanto de la opresión como del placer: historias del armario y el deseo, representaciones de la sexualidad y de la cultura propia.

El efecto desestabilizante de lo queer depende de que haya una presencia queer -es decir, un conjunto de personas que asuman tal identidad, por provisional que sea. Depende sobre todo de la práctica queer, la cual tambalea entre el desafío de actualizar una sexualidad proscrita y el cuestionamiento de la estabilidad de lo que se considera transgresivo. Al nivel de la teoría, "queer" puede entenderse como la señal de la antiidentidad. En cuanto a la práctica política, sin embargo,

\footnotetext{
${ }^{25}$ Le agradezco a Luciano Martínez, no sólo por la información sobre los programas argentinos, sino también por animarme a pensar sobre los cambios recientes en cuanto a las investigaciones universitarias sobre questiones queer.
} 
un movimiento social requiere el fulcro de la identidad para movilizarse. La práctica de la crítica literaria y cultural participa en esos campos aparentemente contradictorios, el de la teoría y el de la política. La paradoja y la ambigüedad de esta postura son inevitables, pero son también un fundamento del análisis queer. De hecho, dos figuras icónicas de la literatura lésbico-gay latinoamericana ponen en tela de juicio la identidad que se les imputa para formular tal crítica. Manuel Puig negaba explícitamente las identidades sexuales; Cristina Peri Rossi las cuestiona implícitamente. ${ }^{26}$ No jugar el juego de las identidades es en sí un desafío queer, sobre todo en los casos de una práctica textual queer al nivel de los personajes, los temas y la estética. ${ }^{27}$ La paradoja atrae; la práctica de la crítica queer es lúdica; el juego va en serio, pero nos divierte jugarlo.

La práctica queer entre hispanistas puede tomar muchas formas, entre ellos el encuiramiento de las fronteras establecidas por las disciplinas y por la geopolítica. Muchas de las colecciones editadas incluyen estudios sobre literatura peninsular y latinoamericana, otras son interdisciplinarias. Algunas cruzan la frontera entre Hispanoamérica y los Estados Unidos para comentar la cultura queer chicano-latina. Tomemos en serio la metáfora: el travesti es el que traversa fronteras de género, el que se niega a reconocer las fronteras convencionales. Es un ilegal, un mojado, un cruzafronteras. Desestabiliza la nación, representa una amenaza a los límites de la sexualidad normativa, del Estado.

El desafío más profundo del verbo queer es que el hecho de encuirar propone desestabilizar la normatividad en todos sus aspectos. Pedro Lemebel reconoce la habilidad de la cultura hegemónica de absorber las prácticas transgresivas, incorporándolas y dejándolas impotentes. Para Lemebel, el vocablo "gay" se ha convertido en un término conservador, ya domado. Insiste en mantener un vocabulario provocativo:

Te aclaro que lo gay no es sinónimo de travesti, marica, trolo, camiona, marimacho o transgénero. Estos últimos flujos del desbande sexual aparecen encintados como multitudes "queer" (raras) después de que lo gay obtuvo su conservador reconocimiento. Quizá son estas categorías las que pueden alterar el itinerario de los azahares gay tan cómodos en el status de la legalización. Nunca fui tan ingenuo ni tan iluso como para jactarme de que la elección erótica me convertía en la condesa de la resistencia, siempre supe que existía la homosexualidad fascista y burguesa ahorcada en la corbata de su auto-represión.

\footnotetext{
${ }^{26}$ Puig, como nota Balderston, "negaba la existencia de identidades homosexual y heterosexual” (El deseo, 11). Véase "The Question of Lesbian Presence” en Kaminsky (1993) para una discusión más amplia de lo resbaladizo que es el término "lésbico" cuando se lo aplica a la literatura.

${ }^{27}$ La estética queer incluye la práctica gay del camp y el interés en el melodrama en el ambiente gay. Véase, por ejemplo, la novela gay mexicana seminal, Melodrama, de Luis Zapata.
} 
La filósofa norteamericana Naomi Scheman explica la necesidad de "encuirar el centro, para centrar al queer". Un Lemebel que insiste en su derecho de comentar no sólo la homosexualidad sino también la pobreza, un Armando Rojas Guardia que anhela vivir su homosexualidad en el espacio público espiritual de una Iglesia católica cuyos ritos incluyan la consagración de las relaciones homosexuales, proponen centrar al queer, o sea encuirar el entorno:

Quiero decir que mientras los maricas poeticemos la maricada está todo bien, en su lugar, en el rincón que le asigna la democracia oficial. Pero cuando se opina sobre etnias, aborto, derechos reproductivos, libertad de culto o políticas económicas, la licencia freak queda cancelada. (Lemebel)

Lemebel propone encuirar la cultura entera y reconoce la resistencia que le espera. La crítica no puede menos que apoyar su proyecto.

BiBLIOGRAFÍA

Albuquerque, Severino J. Tentative Transgressions. Homosexuality, AIDS, and the Theater in Brazil. Madison: U of Wisconsin P, 2004.

Balderston, Daniel. El deseo, enorme cicatriz luminosa. Caracas/Valencia: EXcultura, 1999.

y Donna J. Guy, eds. Sex and Sexuality in Latin America. Nueva York: New York UP, 1997.

y José Quiroga. Sexualidades en disputa. Homosexualidades, literatura y medios de comunicación en América Latina. Buenos Aires: Libros del Rojas, 2005.

Bergmann, Emilie L. y Paul Julian Smith, eds. Entiendes?: Queer Readings, Hispanic Writings. Durham: Duke UP, 1995.

De Lauretis, Teresa. "Sexual Indifference and Lesbian Representation". Theatre Journal 40 (mayo de 1988): 155-177.

Feal, Rosemary Geisdorfer. "Queer Cortázar and the Lectora Macho”. Reading and Writing the Ambiente. Queer Sexualities in Latino, Latin American, and Spanish Cutlure. Susana Chávez-Silverman y Librada Hernández, eds. Madison: $\mathrm{U}$ of Wisconsin P, 2000.

Fernández Rasines, Paloma. "Lesbianas en el mercado: Homoerotismo y mujeres en las pequeñas pantallas” (Comunicación en IX Congreso de la Federación de Asociaciones deAntropología del Estado Español, Barcelona 4-7 de septiembre de 2002): s.p. <http://ankulegi.pangea.org>

Fiol-Matta, Licia. A Queer Mother for the Nation. The State and Gabriela Mistral. Minneapolis: U of Minnesota P, 2002. 
Foster, David William. Gay and Lesbian Themes in Latin American Literature. Austin: U of Texas P, 1991.

Sexual Textualities. Essays on Queer/ing Latin American Writing. Austin: U of Texas P, 1997.

y Roberto Reis, eds. Bodies and Biases. Sexualities in Hispanic Cultures and Literatures. Minneapolis: U of Minneapota P, 1996.

Frye, Marilyn. “Oppression”. The Politics of Reality: Essays in Feminist Theory. Freedom: The Crossing Press, 1983. 1-16.

Irwin, Robert McKee. Mexican Masculinities. Minneapolis: U of Minnesota P, 2003.

Kaminsky, Amy. Reading the Body Politic. Feminist Criticism and Latin American Women Writers. Minneapolis: U of Minnesota P, 1993.

Lemebel, Pedro. Entrevista con Flavia Costa. "La rabia es la tinta de mi escritura". Revista $\tilde{N}$ (14 de agosto de 2004): s.p. <http://www.clarin.com/suplementos/ cultura/2004/08/14/u-813177hm>

Lorde, Audre. The Uses of the Erotic. The Erotic as Power. Berkeley: The Crossing Press, 1978.

Molloy, Sylvia. "Too Wilde for Comfort: Desire and Ideology in Fin-de-siècle Latin America”. Social Text 10/2-3 (1992): 187-201.

y Robert McKee Irwin, eds. Hispanisms and Homosexualities. Durham: Duke UP, 1998.

Muñoz, Carlos. "Identidades translocales y orientación sexual en Caracas (arqueología, genealogía y tecnologías de la orientación sexual)”. Políticas de identidades y diferencias sociales en tiempos de globalización. Daniel Mato, coord. Caracas: FACES - Universidad Central de Venezuela, 2003. <http:// www.globalcult.org.ve/pub/Rocky/libro1/munoz/pdf> 219-55.

Montero, Oscar. "Modernismo and Homophobia: Darío and Rodó”. Sexand Sexuality in Latin America. Daniel Balderston y Donna J. Guy, eds. Nueva York: New York UP, 1997. 101-117.

Oropesa, Salvador A. The Contemporáneos Group. Rewriting Mexico in the Thirties and Forties. Austin: U of Texas P, 2003.

Piedra, “Nationalizing Sissies”. ¿Entiendes? Queer Readings, Hispanic Writings. Emilie L. y Paul Julian Smith, eds. Durham: Duke UP, 1995.

Quinlan, Susan Canty y Fernando Arenas, eds. Lusosex: Gender and Sexuality in the Portuguese Speaking World. Minneapolis: U of Minnesota P, 2002.

Quiroga, José. Tropics of Desire. Interventions from Queer Latino America. Nueva York: New York UP, 2000.

Rubin, Gayle. "Of Catamites and Kings: Reflections on Butch, Gender, and Boundaries”. The Persistent Desire. A Femme-Butch-Reader. Joan Nestle, ed. Boston: Alyson,1992. 
Scheman, Naomi. "Queering the Center by Centering the Queer: Reflections on Transsexuals and Secular Jews". Feminists Rethink the Self. Diana Tietjens Meyers, ed. Boulder: Westview Press, 1997. 124-62.

Sifuentes-Jáuregui, Ben. Transvestism, Masculinity, and Latin American Literature. Genders Share Flesh. Nueva York: Palgrave, 2002.

Smith, Paul Julian. The Body Hispanic. Gender and Sexuality in Spanish and Spanish American Literature. [1989] Oxford: Oxford UP, 1992.

Socorro, Milagros. "Denme mi planilla". El Universal (Caracas, 7 de julio de 2001): s.d.

Spivak, Gayatri Chakravorty. “Criticism, Feminism, and the Institution”(Entrevista con Elizabeth Grosz, 17 de agosto de 1984). The Post-colonial Critic: Interviews, Strategies, Dialogues. Sarah Harasym, ed. New York: Routledge, 1990. 1-16.

Vila, Fefa. "Queerpos que mutan". <http://www.hartza.com/MUTAR.html>

Warner, Michael, ed. Fear of a Queer Planet. Queer Politics and Social Theory. Minneapolis: U of Minnesota P, 1993.

Wittig, Monique. The Straight Mind \& Other Essays. Boston: Beacon Press, 1992.

Yúdice, George. "Contrapunteo estadounidense/latinoamericano de los estudios culturales”. Estudios yotras prácticas intelectuales latinoamericanas en cultura y poder. Daniel Mato, coord. Caracas: Consejo Latinoamericano de Ciencias Sociales (CLACSO) y CEAP, FACES, Universidad Central de Venezuela, 2002. <http://www.globalcult.org.ve/pdf/Yudice.pdf> 339-52.

Zapata, Luis. Melodrama. México: Enjambre, 1983. 